\title{
Synthesis of Pyridine Derivative-based Chemosensor for Formaldehyde Detection
}

\author{
Nurul Hidayah, Bambang Purwono*, Beta Achromi Nurohmah, and Harno Dwi Pranowo \\ Department of Chemistry, Faculty of Mathematics and Natural Sciences, Universitas Gadjah Mada, \\ Sekip Utara, Yogyakarta 55281, Indonesia
}

*Corresponding author:

tel: $+62-85102967033$

email:purwono.bambang@ugm.ac.id

Received: March 8, 2019

Accepted: May 2, 2019

DOI: $10.22146 /$ ijc. 44028

\begin{abstract}
Compound of 3,3'-(4-(2-amino-4,5-dimethoxyphenyl)pyridine-2,6diyl)dianiline (CHP) has been synthesized via three-step synthetic procedure from veratraldehyde as starting material and 4-(4,5-dimethoxy-2-nitrophenyl)-2,6-bis(3nitrophenyl)pyridine (CHP-1) as an intermediate compound. The CHP-1 was reduced using hydrazine hydrate catalyzed by $10 \% \mathrm{Pd} / \mathrm{C}$ to the final target of $\mathbf{C H P}$. The spectroscopic study revealed that $\mathbf{C H P}$ in acetonitrile could detect formaldehyde through fluorescence enhancement and showed color change from yellow to blue under the 365 $n m$ portable ultraviolet lamp as a response. Based on the fluorescence spectra, the emission wavelength of $\mathbf{C H P}$ in acetonitrile was shifted from 526 to $480 \mathrm{~nm}$ after addition of formaldehyde. Limit detection (LOD), selectivity, sensitivity, and computational study geometry of $\mathbf{C H P}$ as a chemosensor for formaldehyde has also been investigated. $\mathbf{C H P}$ could also be applied as a test paper for the detection of formaldehyde qualitatively.
\end{abstract}

Keywords: pyridine; chemosensor; formaldehyde; fluorescence

\section{- INTRODUCTION}

Formaldehyde is usually found in resins that used in manufactures of wood product, building materials, household products, fertilizers, and pesticides. In addition, formaldehyde is also used as a food preservative illegally, likely on fish and meat products, wet noodles, and soybean curds [1]. On the other hand, formaldehyde has serious effects on human health such as irritation of skin, eyes, nose, throat, and causes DNA damage by reacting with nucleophilic material actively [2]. Moreover, a high concentration of formaldehyde exposure has been reported to cause cancer [3]. For a reason, it is necessary to develop a formaldehyde chemosensor in a simple and cost-effective way.

Research regarding the formaldehyde detection method has been carried out, developed, and described, such as using chromatography, spectrophotometry, and enzymatic methods. Li et al. [4] and Yeh et al. [5] determined the formaldehyde level in a sample using HPLC and GC-MS. This method has a disadvantage due to longer analysis time, and complicated tools. Korpan et al. [6] and Nikitina et al. [7] have designed biosensor compounds to detect formaldehyde enzymatically, but it has a low potential because of a lot of interference and depending on the environmental conditions $(\mathrm{pH}$ and temperature). Dar et al. [8] used the Thin Layer Chromatography method for formaldehyde determination, but this method was unable to measure formaldehyde in high concentration. Analysis of spectrophotometric method has been used in this matter. Mohr [9] and Wei et al. [10] have developed a colorimetric method to detect formaldehyde, but this method has a lack of sensitivity. Meanwhile, fluorometric [11-17] has advantages over other methods, namely simpler, faster, cheaper, a great sensitivity, and it can be used for routine analysis [18-20].

Previously, pyridine derivative 4-phenyl-2,6-bis(4aminophenyl)pyridine (CHP-0) has been reported [21] by our group as fluorescence chemosensor of formal dehyde. The sensor shows emission peak shifts from 489 to $442 \mathrm{~nm}$ after addition of formaldehyde. Inspired by their works, we developed a pyridine derivative compound 3,3'-(4-(2-amino-4,5-dimethoxyphenyl) pyridine-2,6-diyl)dianiline (CHP) from veratraldehyde modified with amine group for formaldehyde sensing. 
<smiles>COc1cc(N)c(-c2cc(-c3cccc(N)c3)nc(-c3cccc(N)c3)c2)cc1OC</smiles>

Fig 1. Chemical structure of CHP-0 and CHP

The CHP has a different substituent and position in aryl group compared to CHP-0. CHP could detect formaldehyde and enhanced fluorescence intensity in acetonitrile. This study also discovered that $\mathrm{CHP}$ shows a clearer distinct color change, better selectivity, and sensitivity compared to the previously reported compounds (CHP-0).

\section{- EXPERIMENTAL SECTION}

\section{Materials and Instrumentation}

Materials used for the synthesis were veratraldehyde $\left(\mathrm{C}_{9} \mathrm{H}_{10} \mathrm{O}_{3}\right)$, 3-nitroacetophenone $\left(\mathrm{C}_{8} \mathrm{H}_{7} \mathrm{NO}_{3}\right)$, nitric acid $65 \%$, sulfuric acid $95-98 \%$, ammonium acetate, acetic acid glacial, $\mathrm{Pd} / \mathrm{C} 10 \%$, hydrazine hydrate $80 \%$, ethanol $98 \%$, and distilled water. The solvent used for fluorescence spectra measurement was acetonitrile. These materials and solvent were pro analytic reagents from Merck, except for distilled water.

Equipment used for the synthesis was a set of reflux, electric heater, magnetic stirrer, and laboratory glassware.
Instruments employed for characterization of synthesis product were melting point (Electrothermal 9100), FTIR spectrometer (Shimadzu Prestige 21), Mass Spectrometry (Shimadzu QP-2010S), NMR spectrometer (JEOL JNM-ECZ500R), and spectrofluorophotometer with a $1 \mathrm{~cm}$ standard quartz cell (Shimadzu RF-6000) for fluorescence measurements.

\section{Procedure}

\section{Synthesis of 3,3'-(4-(2-amino-4,5-dimethoxyphenyl) pyridine-2,6-diyl)dianiline (CHP)}

The synthesis of 3,3'-(4-(2-amino-4,5dimethoxyphenyl)pyridine-2,6-diyl)dianiline (CHP) was modified from Tamami and Yeganeh [22] as shown in Scheme 1. A solution of 4-(4,5-dimethoxy-2nitrophenyl)-2,6-bis(3-nitrophenyl)pyridine (CHP-1) in ethanol $(0.6 \mathrm{mmol})$ was added $10 \% \mathrm{Pd} / \mathrm{C}(0.1 \mathrm{~g})$. The mixture solution was stirred and heated about $50{ }^{\circ} \mathrm{C}$, and $80 \%$ hydrazine hydrate $0.8 \mathrm{~mL}$ in $1.5 \mathrm{~mL}$ of ethanol was added slowly using dropping funnel over $1.5 \mathrm{~h}$ of the period. After the addition was completed, the mixture was refluxed for $2-3 \mathrm{~h}$ at $78{ }^{\circ} \mathrm{C}$ (the reaction was monitored by TLC) and filtered while it was still hot. The crude product as solid was obtained from the filtrate. The solid was recrystallized with absolute ethanol as yellowish solid (55\%, $0.19 \mathrm{~g}$, mp $218-219^{\circ} \mathrm{C}$ ). FT-IR $(\mathrm{KBr}) \cup\left(\mathrm{cm}^{-1}\right): 1041$ and 1149 (C-O-C), 1080 and 1257 $(\mathrm{C}-\mathrm{N}), 1589(\mathrm{C}=\mathrm{N}), 3356$ and $3433\left(\mathrm{NH}_{2}\right) ;{ }^{1} \mathrm{H} \mathrm{NMR}(500$ $\left.\mathrm{MHz}, \mathrm{CDCl}_{3}\right) \delta_{\mathrm{H}}(\mathrm{ppm}): 3.23(\mathrm{~s}, 6 \mathrm{H}), 3.84(\mathrm{~s}, 3 \mathrm{H}), 3.87$ (s, 3H), $6.38(\mathrm{~s}, 1 \mathrm{H}), 6.75(\mathrm{dd}, 2 \mathrm{H}, \mathrm{J}=8.0,2.0 \mathrm{~Hz}, 2 \mathrm{H})$, $6.77(\mathrm{~s}, 1 \mathrm{H}), 7.25(\mathrm{t}, 2 \mathrm{H}), 7.47(\mathrm{~d}, 2 \mathrm{H}), 7.55(\mathrm{t}, 2 \mathrm{H}), 7.72$ (s, 2H); ${ }^{13} \mathrm{C} \mathrm{NMR}\left(125 \mathrm{MHz}, \mathrm{CDCl}_{3}\right) \delta_{\mathrm{C}}(\mathrm{ppm}): 56.11$,

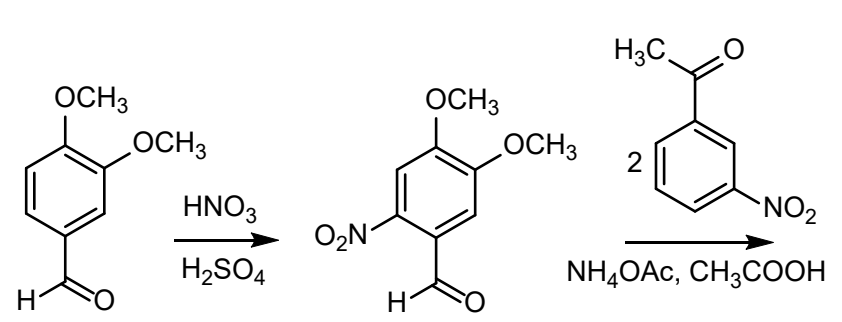<smiles>COc1cc(-c2cc(-c3cccc([N+](=O)[O-])c3)nc(-c3cccc([N+](=O)[O-])c3)c2)c([N+](=O)[O-])cc1OC</smiles>

CHP-1<smiles>COc1cc(N)c(-c2cc(-c3cccc(N)c3)nc(-c3cccc(N)c3)c2)cc1OC</smiles>

CHP

Scheme 1. Synthesis route of compound CHP 
$56.90,101.05,113.89,114.02,116.10,116.70,117.63$, $119.32,129.78,137.80,140.72,142.69,147.00,148.99$, 150.53, 157.65; MS (EI) for $\mathrm{C}_{25} \mathrm{H}_{24} \mathrm{~N}_{4} \mathrm{O}_{2} \mathrm{~m} / \mathrm{z}: 412.0\left(\mathrm{M}^{+}\right)$.

\section{General procedure for fluorescence spectra measurement}

The stock solutions of CHP $\left(2.5 \times 10^{-4} \mathrm{M}\right)$ were prepared in acetonitrile. The $37 \%$ formaldehyde in aqueous solutions was used to make the final concentration of $1 \times 10^{-2} \mathrm{M}$. Formaldehyde concentration of $0,1,3,5,7,9,10,20,40,60,80,100,120,140,160,180$, and $200 \times 10^{-2} \mathrm{M}(0.1 \mathrm{~mL})$ was added into $4 \mathrm{~mL}$ of CHP in acetonitrile solution $\left(2.5 \times 10^{-4} \mathrm{M}\right)$ and then the fluorescence spectra were recorded.

\section{Application of chemosensor as paper strip test}

This procedure was modified from $\mathrm{He}$ et al. [23]. Filter papers were dipped into the CHP in acetonitrile solution $\left(1 \times 10^{-3} \mathrm{M}\right)$ and flicked redundantly to make liquid away. The papers were then put over the formaldehyde solution (37\%) and distilled water (as a negative control) respectively.

To confirm the detection ability of paper strip, meatball as food sample was tested by paper strip loaded with CHP. At first, the meatballs were immersed in $1 \mathrm{M}$ formaldehyde solution for overnight. The meatballs were then weighed $(1 \mathrm{~g})$, crushed with a mortar, added with distilled water and filtered. The filtrate obtained was diluted to $25 \mathrm{~mL}$. At last, meatball filtrate was dripped into the paper strip loaded with CHP compound.

\section{Density Functional Theory (DFT) calculations}

Computational studies using DFT based on the Becke three-parameter exchange/Lee-Yang-Parr correlation hybrid functional (B3LYP), PCM Solvent Model with acetonitrile as a solvent, and the 6-31G basis set as implemented in the Gaussian 09 programs were carried out for the geometry optimizations of CHP and CHP-HCHO.

\section{- RESULTS AND DISCUSSION}

\section{Synthesis of CHP}

The chemosensor of CHP was produced via threestep synthetic procedures starting from veratraldehyde. The nitration reaction of veratraldehyde produced in $95 \%$ yield, followed condensation of 6-nitroveratraldehyde with 3-nitroacetophenone yielded a compound of CHP-1 in 20\% yield. The final step was the reduction of CHP-1 with $80 \%$ hydrazine hydrate and $10 \%$ Palladium on carbon and resulted in the CHP in a 55\% yield. The chemical structure of CHP was confirmed by FT-IR, MS, ${ }^{1} \mathrm{H}$ and ${ }^{13} \mathrm{C}$ NMR.

\section{Fluorescence Response of CHP toward Formaldehyde}

Compound CHP in acetonitrile $\left(2.5 \times 10^{-4} \mathrm{M}\right)$ was added with $37 \%$ formaldehyde (HCHO) in aqueous solution to examine the response as a chemosensor toward formaldehyde. It has been revealed that CHP was showed an obvious color change from yellow to blue under the $365 \mathrm{~nm}$ portable ultraviolet lamp, implying that chemosensor CHP could be used for qualitative determination of formaldehyde. The interaction produced a blue-shift of emission wavelength from $526 \mathrm{~nm}$ to $480 \mathrm{~nm}$ with excitation at $363 \mathrm{~nm}$ (before and after the addition of formaldehyde) (see Fig. 2).

Upon the addition of equivalents of formaldehyde in acetonitrile, the emission intensity at $480 \mathrm{~nm}$ is greatly enhanced. In width concentration range of formaldehyde from 0 to $1.2 \mathrm{M}$, the fluorescence peak intensity of CHP showed a good linear relationship with

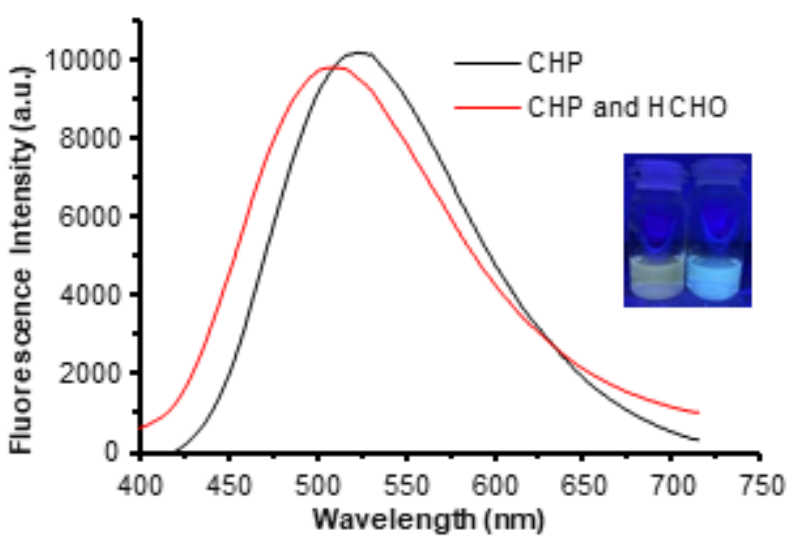

Fig 2. Fluorescence spectra of CHP $\left(2.5 \times 10^{-4} \mathrm{M}\right.$ in acetonitrile) before and after addition of $50 \mu \mathrm{L} 37 \%$ formaldehyde-water solution with excitation at $363 \mathrm{~nm}$. Inset: Photographs of compound CHP $\left(2.5 \times 10^{-4} \mathrm{M}\right.$ in acetonitrile) before (left) and after (right) addition of formaldehyde under $365 \mathrm{~nm}$ portable UV lamp 

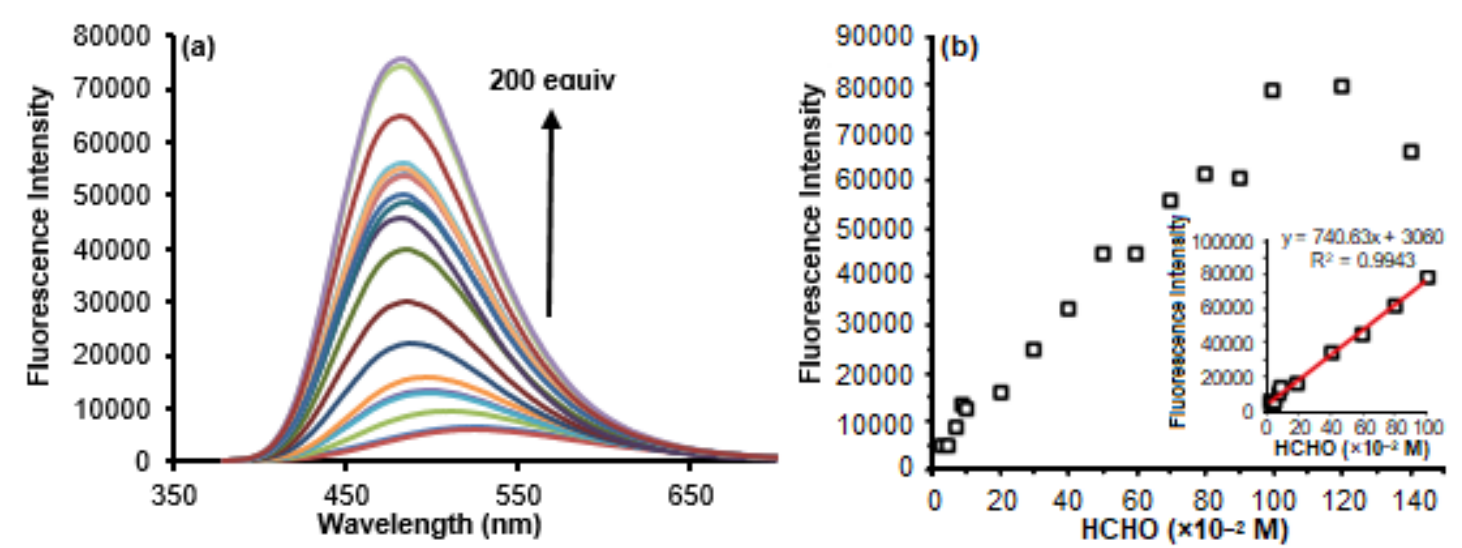

Fig 3. (a) Emission spectra of CHP $\left(2.5 \times 10^{-4} \mathrm{M}\right.$ in acetonitrile $)$ upon addition of formaldehyde-water solution (0-200 equiv.) with excitation at $363 \mathrm{~nm}$; (b) Emission intensity of CHP at $480 \mathrm{~nm}$ as a function of formaldehyde concentration $(0-1.4 \mathrm{M})$. Inset: Linear relationship between fluorescence intensity and the concentration of formaldehyde

the formaldehyde concentration $(\mathrm{R}=0.9943)$ (see Fig. 3). Thus, this result indicates that formaldehyde can be quantitatively detected in a wider concentration range. The detection limit (LOD) of CHP was calculated with the formula: $\mathrm{LOD}=3 \sigma / \mathrm{m}$, where $\sigma$ represents the standard deviation of blank measurements and $m$ is the slope between intensity versus sample concentration [24]. The calculated detection limit (LOD) of probe CHP for formaldehyde was found to be $0.58 \mathrm{mM}$. The results led us to conclude that CHP could be applied as an effective fluorescence chemosensor for formaldehyde.

\section{Formaldehyde Sensing Mechanism of CHP}

Based on the structure, two amines from CHP reacted with formaldehyde to form imine functional groups (Scheme 2) and showed fluorescence enhancement that could be described by the prohibition of PET process upon sensing. To verify the possible response mechanism, the molecular geometries of probe CHP and the product from the reaction of CHP with formaldehyde were optimized by Density Functional Theory (DFT). As shown in Fig. 4, the frontier orbital diagram indicates that the HOMO energy of the fluorophore $(-5.249 \mathrm{eV})$ was lower than the HOMO energy of the aniline $(-5.220 \mathrm{eV})$ before the reaction CHP with formaldehyde, which implied that PET process could happen from the aniline moieties to the pyridine fluorophore. However, after reaction of CHP with formaldehyde, electron transfer from<smiles>COc1cc(N)c(-c2cc(-c3cccc(N)c3)nc(-c3cccc(N)c3)c2)cc1OC</smiles>

CHP

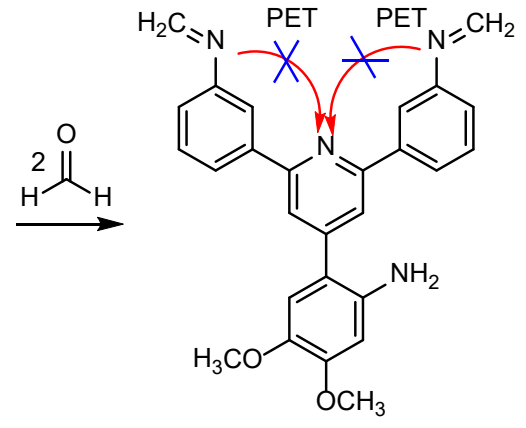

CHP-HCHO
Scheme 2. Possible reaction mechanism of CHP with formaldehyde

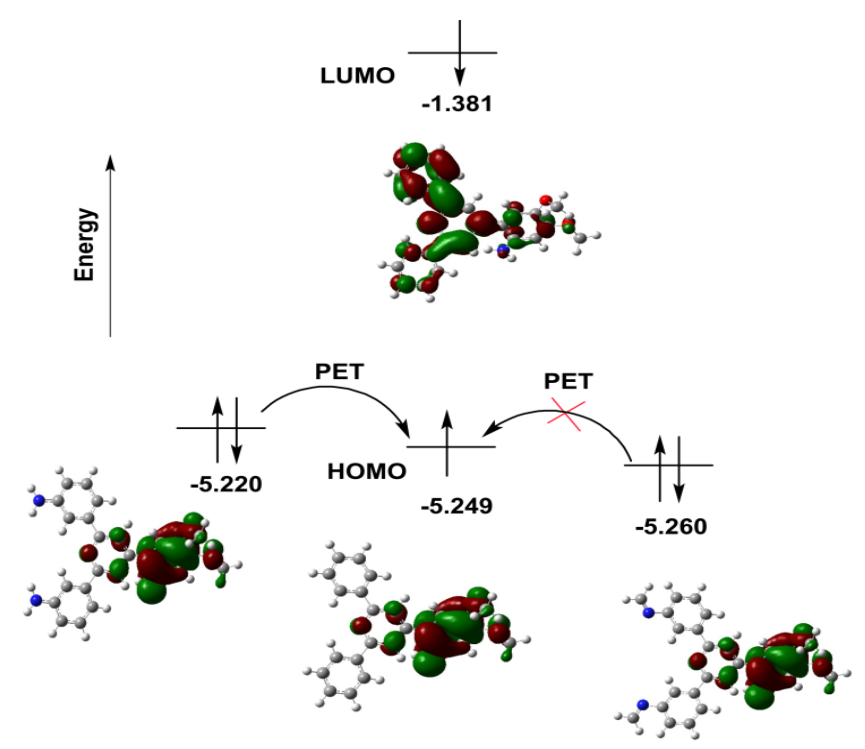

Fig 4. Frontier molecular orbital energies of CHP in different conditions that are relevant to PET process 
the electron-deficient imine moieties to the electron-rich pyridine fluorophore became difficult to occur (blocked the PET process), because the HOMO energy of imine $(-5.260 \mathrm{eV})$ was lower than the pyridine fluorophore.

\section{Kinetic Study and Selectivity}

The time course of the fluorescence spectra of CHP toward formaldehyde has also been studied. As shown in Fig. 5, emission intensity increased gradually and reached a maximum in $65 \mathrm{~min}$ after the addition of formaldehyde.

To examine the selectivity of CHP toward formaldehyde, various of aldehyde compounds were added into CHP in acetonitrile. As shown in Fig. 6, the addition of formaldehyde produced a significant enhancement in the fluorescence intensity at $480 \mathrm{~nm}$, whereas the other aldehyde compounds did not generate significant fluorescence enhancement to the CHP solution.

To further investigate the selectivity of CHP as a formaldehyde sensing, the fluorescence intensity of CHP upon addition of simultaneous formaldehyde and various aldehyde was recorded. Fig. 7 presented that all of the selected aldehyde compounds have no interference in the detection of formaldehyde. This result implies that CHP has good selectivity for formaldehyde.

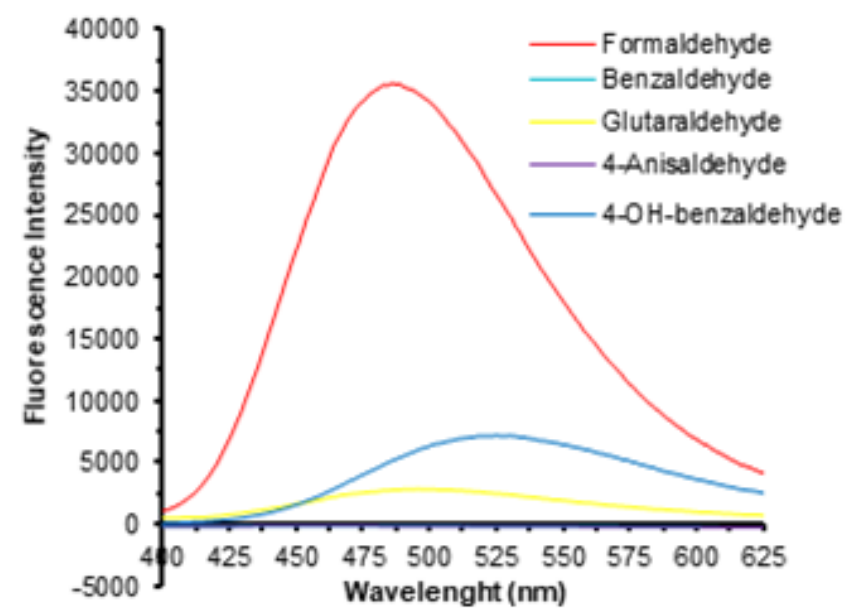

Fig 6. Emission spectra of CHP $\left(1 \times 10^{-3} \mathrm{M}\right.$ in acetonitrile $)$ after addition of different aldehyde compounds with excitation at $363 \mathrm{~nm}$

\section{Application of CHP as Test Paper}

A simple test paper was developed to demonstrate the practical application of chemosensor CHP and used to detect formaldehyde visually. As shown in Fig. 8, the presence of formaldehyde on the paper showed strong fluorescence relative to the paper over the water. The phenomenon was clearly observed by naked eyes under a portable UV lamp with excitation at $365 \mathrm{~nm}$. Then, to demonstrate the applicability of paper strip for formaldehyde detection directly, meatball as a food sample was tested. As a result, paper strip added meatball

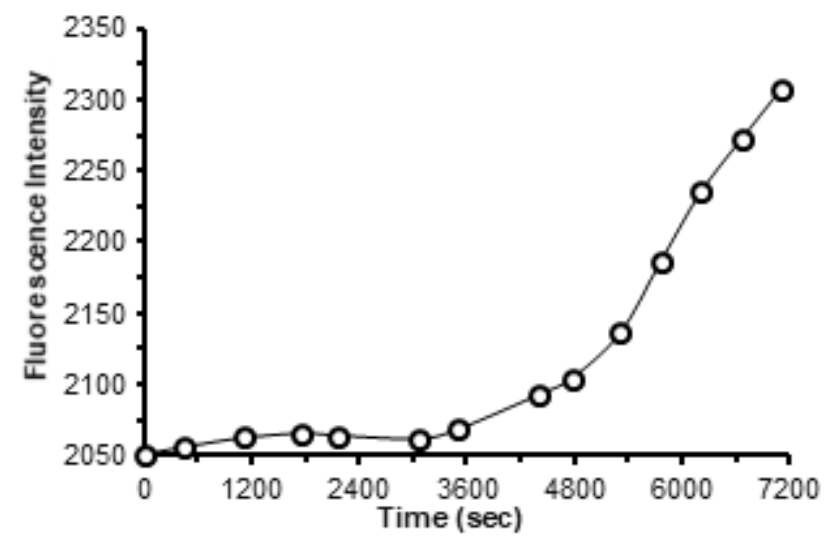

Fig 5. Time-course fluorescence response spectra of CHP $\left(1.0 \times 10^{-3} \mathrm{M}\right.$ in acetonitrile) toward formaldehyde (200 equiv.)

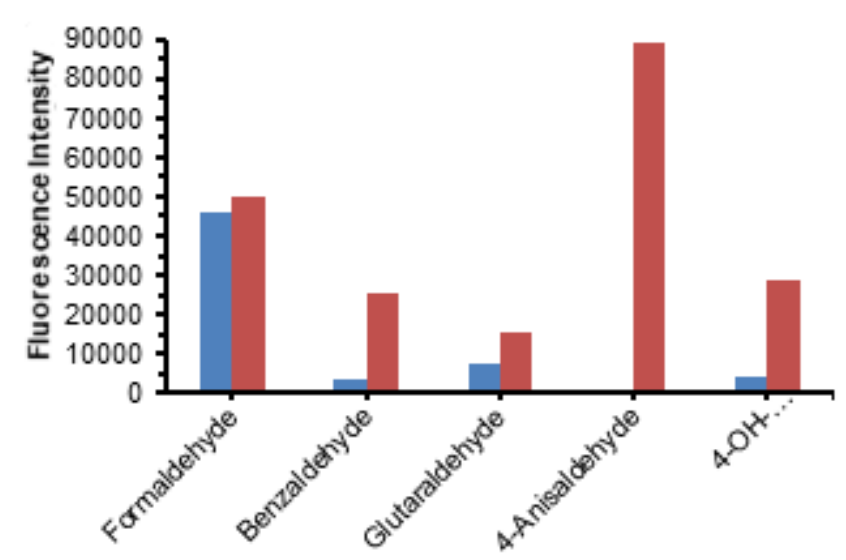

Fig 7. Fluorescence intensity of CHP $\left(1 \times 10^{-4} \mathrm{M}\right.$ in acetonitrile) at $480 \mathrm{~nm}$ after addition of different aldehyde compounds (200 equiv.) (blue bars); the mixture of CHP and formaldehyde after addition of other aldehyde compounds (red bars) 


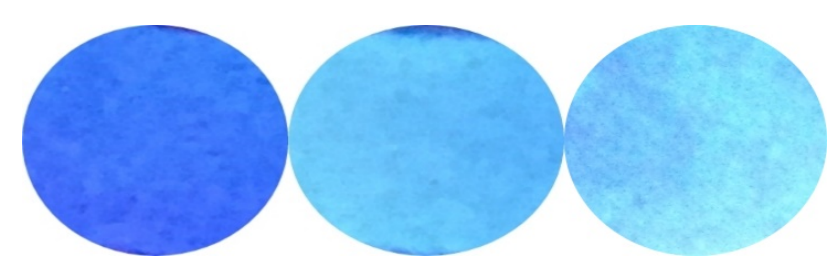

Fig 8. Photographs of probe CHP as test paper for the detection of formaldehyde under $365 \mathrm{~nm}$ portable UV lamp (filter paper loaded with CHP in acetonitrile over the water (left), formaldehyde (center), and application of meatball test (right)

filtrate containing formaldehyde showed bright appearance, implying that the test paper could be used to detect formaldehyde qualitatively.

\section{- CONCLUSION}

In conclusion, chemosensor-based pyridine derivative of formaldehyde has been developed, which shows high sensitivity and selectivity fluorescence recognition for formaldehyde in acetonitrile. The chemosensor produces a blue-shift from 562 to $480 \mathrm{~nm}$ with excitation at $363 \mathrm{~nm}$. Formaldehyde can be detected quantitatively in a concentration range from $0-1.2 \mathrm{M}$, and the detection limit was $0.58 \mathrm{mM}$. In addition, the test paper loaded CHP was successfully applied in the detection of formaldehyde qualitatively.

\section{- ACKNOWLEDGMENTS}

Authors are grateful to the Ministry of Research, Technology, and Higher Education of the Republic of Indonesia (RISTEK DIKTI) for financial support this study through Master Program of Education Leading to Doctoral Degree for Excellent Graduates (PMDSU) (1511/E4.4/2015). Authors also thankful to the memory of Dr.rer.nat. Ria Armunanto, M.Si. for computational contribution.

\section{- REFERENCES}

[1] Nowshad, F., Islam, M.N., and Khan, M.S., 2018, Concentration and formation behavior of naturally occurring formaldehyde in foods, Agric. Food Secur., 7 (1), 17.

[2] Merk, O., and Speit, G., 1998, Significance of formaldehyde-induced DNA-protein crosslinks for mutagenesis, Environ. Mol. Mutagen., 32 (3), 260268.

[3] Cogliano, V.J., Grosse, Y., Baan, R.A., Straif, K., Secretan, M.B., and El Ghissassi, F., 2005, Summary of IARC monographs on formaldehyde 2butoxyethanol and 1-tert-butoxy-2-propanol, Environ. Health Perspect., 113 (9), 1205-1208.

[4] Li, J., Zhu, L., and Ye, L., 2007, Determination of formaldehyde in squid by high-performance liquid chromatography, Asia Pac. J. Clin. Nutr., 16 (Suppl. 1), 127-130.

[5] Yeh, T.S., Lin, T.C., Chen, C.C., and Wen, H.M., 2013, Analysis of free and bound formaldehyde in squid and squid products by gas chromatographymass spectrometry, J. Food Drug Anal., 21 (2), 190197.

[6] Korpan, Y.I., Gonchar, M.V., Starodub, N.F., Shulga, A.A., Sibirny, A.A., and Elskaya, A.V., 1993, A cell biosensor specific for formaldehyde based on $\mathrm{pH}$ - sensitive transistors coupled to methylotrophic yeast cells with genetically adjusted metabolism, Anal. Biochem., 215 (2), 216-222.

[7] Nikitina, O., Shleev, S., Gayda, G., Demkiv, O., Gonchar, M., Gorton, L., Csöregi E., and Nistor M., 2007, Bi-enzyme biosensor based on $\mathrm{NAD}^{+}$- and glutathione-dependent recombinant formaldehyde dehydrogenase and diaphorase for formaldehyde assay, Sens. Actuators, B, 125, 1-9.

[8] Dar, A., Shafique, U., Anwar, J., Zaman, W., and Naseer, A., 2016, A simple spot test quantification method to determine formaldehyde in aqueous samples, J. Saudi Chem. Soc., 20 (Suppl. 1), S352S356.

[9] Mohr, G.J., 2003, New chromoreactands for the detection of aldehydes, amines and alcohols, Sens. Actuators, B, 90 (1-3), 31-36.

[10] Wei, K., Ma, L., Ma, G., Ji, C., and Yin, M., 2019, A two-step responsive colorimetric probe for fast detection of formaldehyde in weakly acidic environment, Dyes Pigm., 165, 294-300.

[11] Song, H., Rajendiran, S., Kim, N., Jeong, S.K., Koo, E., Park, G., Thangadurai, T.D., and Yoon, S., 2012, A tailor designed fluorescent 'turn-on' sensor of 
formaldehyde based on the BODIPY motif, Tetrahedron Lett., 53 (37), 4913-4916.

[12] Zhou, W., Dong, H., Yan, H., Shi, C., Yu, M., Wei, L., and Li, Z., 2015, HCHO-reactive molecule with dualemission-enhancement property for quantitatively detecting HCHO in near $100 \%$ water solution, Sens. Actuators, B, 209, 664-669.

[13] Liu, C., Shi, C., Li, H., Du, W., Li, Z., Wei, L., and Yu, M., 2015, Nanomolar fluorescent quantitative detection of formaldehyde with a 8-hydroxyquinoline derivative in aqueous solution and electrospun nanofibers, Sens. Actuators, B, 219, 185-191.

[14] Roth, A., Li, H., Anorma, C., and Chan, J., 2015, A reaction-based fluorescent probe for imaging of formaldehyde in living cells, J. Am. Chem. Soc., 137 (34), 10890-10893.

[15] Dong, B., Song, X., Tang, Y., and Lin, W., 2016, A rapid and facile fluorimetric method for detecting formaldehyde, Sens. Actuators, B, 222, 325-330.

[16] Zhou, Y., Yan, J., Zhang, N., Li, D., Xiao, S., and Zheng, K., 2018, A ratiometric fluorescent probe for formaldehyde in aqueous solution, serum and air using aza-cope reaction, Sens. Actuators, B, 258, 156162.

[17] Bi, A., Gao, T., Cao, X., Dong, J., Liu, M., Ding, N., Liao, W., and Zeng, W., 2018, A novel naphthalimidebased probe for ultrafast, highly selective and sensitive detection of formaldehyde, Sens. Actuators, B, 255, 3292-3297.

[18] Li, Q., Oshima, M., and Motomizu, S., 2007, Flow- injection spectrofluorometric determination of trace amounts of formaldehyde in water after derivatization with acetoacetanilide, Talanta, 72 (5), 1675-1680.

[19] Indang, M.N., Abdulamir, A.S., Bakar, A.A., Salleh, A.B., Lee, Y.H., and Azah, Y.N., 2009, A review: Methods of determination of health-endangering formaldehyde in diet, Res. J. Pharmacol., 3 (2), 31-47.

[20] Chen, Y., Shi, W., Hui, Y., Sun, X., Xu, L., Feng, L., and Xie, Z., 2015, A new highly selective fluorescent turn-on chemosensor for cyanide anion, Talanta, 137, 38-42.

[21] Ovianto, D., Sugiharta, I.B.A.R., and Purwono, B., 2017, Synthesis of 4-phenyl-2,6-bis(4-aminophenyl) pyridine compound and study of their fluorescence behaviour for formaldehyde sensing, Int. J. ChemTech Res., 10 (9), 918-923.

[22] Tamami, B., and Yeganeh, H., 2001, Synthesis and characterization of novel aromatic polyamides derived from 4-aryl-2,6-bis(4-aminophenyl) pyridines, Polymer, 42 (2), 415-420.

[23] He, L., Yang, X., Ren, M., Kong, X., Liu, Y., and Lin, W., 2016, An ultra-fast illuminating fluorescent probe for monitoring formaldehyde in living cells, shiitake mushrooms, and indoors, Chem. Commun., 52 (61), 9582-9585.

[24] Joshi, B.P., Park, J., Lee, W.I., and Lee, K.H., 2009, Ratiometric and turn-on monitoring for heavy and transition metal ions in aqueous solution with a fluorescent peptide sensor, Talanta, 78 (3), 903-909. 